\title{
EFEKTIVITAS SERBUK KULIT DUKU (Lansium Domesticum Corr) SEBAGAI MAT ELEKTRIK DALAM MEMBUNUH NYAMUK Culex sp
}

Rizky Nabilah S*, Ngadino, Hadi Suryono

Jurusan Kesehatan Lingkungan, Poltekkes Kemenkes Surabaya

*Email korespondensi: nabilahsafitri25@gmail.com

\begin{abstract}
ABSTRAK
Penyakti filariasis merupakan penyakit bersumber vektor yakni nyamuk Culex sp yang penyebarannya akan semakin luas jika tidak dikendalikan. Pengendalian nyamuk dengan menggunakan insektisida kimia secara kontinyu mengakibatkan resistensi pada nyamuk dan dapat mencemari lingkungan. Kulit buah duku dapat digunakan untuk membunuh nyamuk Culex sp karena memiliki kandunga senyawa aktif Triterpen, flavonoid, dan Saponin. Tujuan penelitian ini yaitu untuk menganalisis efektifitas serbuk kulit duku (Lansium domesticum corr) sebagai mat elektrik dalam membunuh nyamuk Culex sp.

Jenis penelitian ini menggunakan eksperimen murni dengan post test only control grup design. Penelitian ini menggunakan 25 ekor nyamuk Culex sp untuk masing-masing 4 variasi berat kulit serbuk duku yaitu $0,125 \mathrm{gr}, 0,25 \mathrm{gr}, 0,5 \mathrm{gr}$, dan $1 \mathrm{gr}$ selama 60 menit dengan pengulangan sebanyak 5 kali. Analisis data mengguankan uji one away ANOVA dan analisis probit.

Hasil yag diperoleh menunjukkan bahwa ada perbedaan rata-rata kematian nyamuk Culex sp berdasarkan variasi berat serbuk kulit duku yang digunakan dengan hasil uji one away ANOVA $p=0,000$. Perbedaan rata-rata kematian nyamuk Culex $s p$ disebabkan karena perbedaan jumlah bahan aktif pada masing-masing variasi serbuk kulit duku. Hasil analisis probit didapatkan $\mathrm{LD}_{50}$ pada konsentrasi berat kulit buah duku 0,392 gr.

Penelitian ini menyimpulkanbahwa ada perbedaan jumlah kematian nyamuk Culex sp dengan variasi berat kulit buah duku (Lansium domesticum corr). Perlu dilakukan penelitian lebih lanjut untuk meningkatkan berat kulit buah duku (Lansium domesticum corr) untuk mendapatkan daya bunuh $100 \%$ dengan lama waktu pengamatan 24 jam.
\end{abstract}

Kata kunci : Kulit duku, mat elektrik, nyamuk Culek $s p$

\section{PENDAHULUAN}

Penyakit filariais (kaki gajah) merupakan penyakit menular menahun yang disebabkan oleh cacing filaria yang menyerang saluran dan kelenjar getah bening. Salah satunya vektor penyebab penyakit filariasis adalah nyamuk Culex $s p$.

Pada tahun 2016 dilaporkan sebanyak 29 Provinsi dari 34 Provinsi di Indonesia yang dinyatakan endemis Filariasis. Selanjutnya dari 29 Provinsi tersebut ada 239 Kabupaten/Kota endemis filariasis hingga diperkirakan sebanyak 102.279.739 orang yang tinggal di Kabupaten/Kota endemis tersebut beresiko terinfeksi filariasis. Berdasarkan data yang dilaporkan oleh Dinas Kesehatan Provinsi dan hasil survei Indonesia, kasus kronis filariasis dari 2002 hingga 2014 terus meningkat. Tahun 2015, kasus filariasis manurun menjadi 13.032 kasus dari 14.932 pada Tahun 2014.(kemenkes RI, 2016). Menurut Data Dinas Kesehatan Provinsi Jawa Timur pada tahun 2016 jumlah seluruh kasus filariasis sejumlah 351 kasus tercatat di 38 Kabupaten/Kota. (Dinas Prov Jatim, 2016)

Penanggulangan penyakit filariasis, Indonesia melaksanakan program eliminasi filariasis pada Tahun 2020 yang sesuai dengan ketetapan WHO tentang kesepakatan Global Elliminasi Filariasis Tahun 2020 ( Global goal of elimination of lymphatic filariasis as public healt problem by the year 2020). Untuk melaksanakan kegiatan tersebut WHO telah menetapkan metode pemberantasan dengan memberikan pengobatan masal menggunakan DEC (diethylcarbonazine) $6 \mathrm{mg} / \mathrm{kg}$ BB dan Albendazol $400 \mathrm{mg}$ setahun sekali selama 5-10 tahun. (Permenkes, 2014).

Pencegahan penyakit dengan melakukan pengendalian vektor bertujuan untuk menurunkan kasus tersebut dan 
menurunkan populasi vektor sehingga tidak lagi beresiko untuk terjadinya penularan penyakit yang kontak antara vektor dan manusia atau masyarakat. (Yudhastuti, 2011).

Pengendalian vektor dapat dilakukan dengan berbagai cara yaitu secara fisikmekanik. Biologi, dan kimia. Upaya pengendaia tersebut yang lebih banyak digunakan yaitu pengendalian secara kimia yang lebih praktis, seperti penggunaan anti nyamuk elektrik.

Penggunaan bahan kimia berdampak bagi kesehatan manusia dan takkala penting mengakibatkan terjadinya pencemaran terhadap lingkungan alam sekitar dan dapat mengganggu kesehatan. Penggunaan insektisida berbahan kimia (sintetik) secara terus menerus akan mengakibatkan nyamuk menjadi resisten

Buah duku (Lansium domesticum corr) merupakan salah satu tanaman asli indonesia. Salah satunya di Daerah Palembang penghasil buah duku. Buah duku memiliki manfaat sebagai insektisida nabati yang terdapat pada kulit buah duku (Lansium domesticum corr) yang biasa dianggap sampah bagi masyarakat, pada umumnya dapat membunuh nyamuk. Kulit buah duku (Lansium domesticum corr) dapat dijadikan sebagai bahan untuk pembuatan insektisida nabati, karena kulit buah duku memiliki kandungan senyawa aktif triterpen dan ekstrak metanol kulit buah duku menggandung flavonoid dan saponin.

Tujuan dari penelitian ini yaitu menganalisis efektifitas serbuk kulit duku (Lansium domesticum corr) sebagai mat elektrik dalam membunuh nyamuk Culex $s p$

\section{METODE PENELITIAN}

Penelitian ini merupakan jenis penelitian eksperimen murni dengan menggunakan rancangan posttest only control grup design yang terdiri dari kelompok kontrol dan perlakuan eksperimen. (Notoadmojo, 2012).

Objek penelitian ini adalah kulit duku (Lansium domesticum corr) sebagai mat elektrik dengan variasi berat $0,125 \mathrm{gr}$, 0,225gr, 0,5 gr, $1 \mathrm{gr}$ dan kontrol. Penelitian ini menggunakan 625 ekor nyamuk Culex $s p$ dan dibagi menjadi 25 ekor pada masing-maing perlakuan dengan penggulangan sebanyak 5 kali dan pengamatan kematian nyamuk selama 60 menit

Alat yang digunakan dalam pembuatan mat elektrik kulit duku yaitu timbangan analitik, Blender, Mesh, cetakan mat elektrik, Alat Mat elektrik, Kotak pengujian, Aspirator, Thermometer untuk mengukur suhu ruanga dan Hygrometer untuk mengukur kelembaban ruangan.

Bahan yang digunakan dalam pembuatan mat elektrik kulit duku adalah serbuk kulit duku dengan berat $0,125 \mathrm{gr}$, 0,25gr, 0,5gr dan $1 \mathrm{gr}$, tepung tapioka, aqusadest

Cara pembuatan mat elektrik kulit buah duku :

1. Jemur kulit buah duku

2. Setelah kering, blender hingga halus

3. Simplisia serbuk yang diperoleh diayak menggunakan mash $40 / 80$

4. Buat amilim $10 \%$ dari campuran tepung tapioka dengan aquadest, kemudian didihkan. Amilim digunakan sebagai pelekat.

5. Campukan amilum dengan simlisia kulit duku dengan variasi berat (0,5 gram, 1 gram, 2 gram dan 4 gram) hingga tercampur secara merata

6. Cetak gingga berbentuk kotak dengan ukuran $3,5 \mathrm{~cm} \times 2 \mathrm{~cm}$, keringkan dengan dianginanginkan selama 2-3 hasi sampai mengeras.

Langkah-langkah melakukan perlakuan yaitu antara lain:

1. Menyiapkan kotak pengujian

2. Memasukkan variasi berat mat elektrik kulit duku ke alat mat elektrik

3. Ukur suhu dan kelembaban ruang penelitian

4. Ambil 25 ekor nyamuk Culex $s p$ betina kedalam masig-masing kotak pengujian dan beri label

5. Letakkan mat elektrik kulit duku kedalam kotak pengujian, kecuali kontrol tidak diberi perlakuan 
6. Amati jumlah kematian nyamuk Culex $s p$ yang terpapar mat elektrik kulit duku selama 60 menit perlakuan

Teknik pengumpulan data diperoleh dari hasil pengamatan langsung yang dilakukan di Laboratorium Entomologi Jurusan Kesehatan Lingkungan Surabaya. Analisis data dalam penelitian ini menggunakan uji One Way ANOVA dan analisis probit

\section{HASIL DAN PEMBAHASAN \\ Jumlah kematian nyamuk Culex sp}

Tabel 1

JUMLAH KEMATIAN NYAMUK CUlex sp DENGAN PEMAPARAN MAT KULIT BUAH DUKU (Lansium domesticum corr)

\begin{tabular}{ccccccccc}
\hline $\begin{array}{c}\text { Berat } \\
\text { (gram) }\end{array}$ & \multicolumn{1}{c}{ I } & II & III & IV & V & $\begin{array}{c}\text { Jumlah } \\
\text { Nymuk } \\
\text { Uji }\end{array}$ & $\begin{array}{c}\text { Rata- } \\
\text { rata }\end{array}$ & $\begin{array}{c}\text { Persentase } \\
\text { (\%) }\end{array}$ \\
\hline Kontrol & 0 & 0 & 0 & 0 & 0 & 25 & 0 & $0 \%$ \\
0,125 & 7 & 9 & 8 & 8 & 9 & 25 & 8 & $32 \%$ \\
0,25 & 9 & 10 & 12 & 11 & 12 & 25 & 11 & $44 \%$ \\
0,5 & 13 & 14 & 14 & 16 & 15 & 25 & 14 & $56 \%$ \\
1 & 16 & 17 & 17 & 18 & 17 & 25 & 17 & $68 \%$ \\
\hline
\end{tabular}

Berdasarkan Tabel 1 diketahui bahwa rata-rata kematian nyamuk Culex $s p$ selama 60 menit pemaparan diantara kelima berat tersebut, didapatkan kematian nyamuk Culex sp tertinggi pada berat $1 \mathrm{gr}$ sebanyak 17 ekor $(68 \%)$, kematian nyamuk terendah pada berat $0,125 \mathrm{gr}(32 \%)$, dan tidak terdapat kematian nyamuk Culex $s p$ pada kontrol. Pada hasil pengamatan, kematian nyamuk Culex sp yang diberikan perlakuan dengan berbagai variasi berat kulit buah duku (Lansium domesticum corr) dengan metode mat elektrik akan mengalami perubahan tingkah laku akibat dari paparan mat elektrik kulit buah duku maka nyamuk yang semula bergerak aktif akan berubah menjadi lemban, sulit bergerak, pingsan dan mati. Hal tersebut disebabkan adanya bahan aktif yang berperan pada kematian nyamuk. Semakin tinggi berat mat elektrik kulit duku yang digunakan maka semakin banyak jumlah kematian nyamuk Culex $s p$

Pada penelitian ini dilakukan pemaparan mat elektri kulit buah duku (Lansium domesticum corr) terhadap nyamuk Culex $s p$ betina, hal ini disebabkan perilaku nyamuk yang menghisap darah manusia untuk peamatangan telurnya, sementara nyamuk jantan hanya menghisap sari tumbuhan.
Umur nyamuk yang digunakan yakni usia 2-5 hari yang merupakan rentang umur terbaik dari nyamuk dimana ketahanan tubuh nyamuk masih kuat dan sudah produktif. Pada umur dibawah 2 hari, keadaan fisik nyamuk masih lemah sehingga akan mempermudah kematian pada nyamuk, sedangkan pada umur diatas 5 hari ketahanan tubuh nyamuk semakin menurun yang akan mengakibatkan meningkatnya resiko kematian. (Jaya,I. 2017).

\section{Analisis Pengaruh suhu dan kelembaban terhadap jumlah kematian nyamuk Culex sp}

Berdasarkan Tabel. 2 Hasil pengukuran suhu dan kelembaban ruang penelitian didapakan pengukuran suhu sebesar $26,3^{\circ} \mathrm{C}$, yang berarti sesuai dengan suhu optimum untuk perkembangan nyamuk yaitu berkisat antara $25^{\circ} \mathrm{C}-30^{\circ} \mathrm{C}$. Apabila suhu kurang dari $10^{\circ} \mathrm{C}$ atau lebih dari $40^{\circ} \mathrm{C}$ pertumbuhan nyamuk akan berhenti sama sekali dan kelembaban sebesar $63,5 \%$, Kelembaban juga berpengaruh terhadap nyamuk, tingkat kelembaban $60 \%$ merupakan batas paling rendah untuk meningkatkan hidupnya nyamuk.. Pada kelembaban yang tinggi nyamuk menjadi lebih efektif dan lebih sering menggigit, sehingga meningkatkan penularan. (Masriadi, 2017). 
Tabel 2

HASIL PENGUKURAN SUHU DAN KELEMBABAN

\begin{tabular}{cccc}
\hline No. & Berat $($ gram $)$ & Suhu $\left({ }^{\circ} \mathrm{C}\right)$ & Kelembaban $(\%)$ \\
\hline 1. & Kontrol & 26,2 & 63,2 \\
2. & 0.125 & 26,4 & 63,6 \\
3. & 0,25 & 26,4 & 63,4 \\
4. & 0,5 & 26,3 & 63,4 \\
5. & 1 & 26,2 & 63,7 \\
& Rata-rata & 26,3 & 63,5 \\
\hline
\end{tabular}

\section{Analisis Perbedaan Berat Mat Elektrik Kulit Duku (Lansium domesticum corr) terhadap kematian nyamuk Culex sp}

Tabel 3

UJI ONE WAY ANOVA JUMLAH KEMATIAN NYAMUK CUleX sp TERHADAP VARIASI BERAT KULIT BUAH DUKU (Lansium domesticum corr)

\begin{tabular}{cccccc}
\hline Keterangan & $\begin{array}{c}\text { Sum of } \\
\text { Squares }\end{array}$ & Df & $\begin{array}{c}\text { Mean } \\
\text { Square }\end{array}$ & $F$ & Sig. \\
\hline Between Groups & 861,040 & 4 & 215,260 & 256,262 & 0,000 \\
Within Groups & 16,800 & 20 & 0,840 & & \\
Total & 877,840 & 24 & & & \\
\hline
\end{tabular}

Berdasarkan Tabel 3 hasil uji one way Anova didapatkakn nilai signifikan atau $\mathrm{p}=0,000$ maka $\mathrm{p}<0,05$ maka $\mathrm{H}_{0}$ ditolak, hal ini menyatakan bahwa ada perbedaan rata-rata kematian nyamuk Culex $s p$ yang mati akibat mat elektrik kulit duku (Lansium domesticum corr) dengan berat $0,125 \mathrm{gr}, 0,25 \mathrm{gr}, 0,5 \mathrm{gr}$ dan $1 \mathrm{gr}$ dengan lama perlakuan 60 menit. Terjadinya kematian pada nyamuk Culex $s p$ pada berbagai variasi berat yang diberikan, disebabkan oleh banyaknya bahan aktif yang terhirup oleh nyamuk Culex $s p$. Bahan aktif yang terkandung dalam kulit duku (Lansium domesticum corr) yaitu flavonoid, saponin dan triterpenoid.

Bahan aktif yang berpengaruh adalah flavonoid karena berperan dalam menyebabkan kematian pada nyamuk Culex $s p$ melalui pernafasan. Masuknya flavonoid kedalam tubuh serangga yaitu melalui sistem pernafasan berupa spirakel yang terdapat dipermukaan tubuh dan menimbulkan kelemasan pada saraf serta terdapat kerusakan pada spirakel yang menyebabkan serangga tidak dapat bernafas dan akhirnya mati. Saponin masuk melalui dinding tubuh serangga dan bersifat racun, saponin juga dapat mengiritasi mukosa pencernaan yang mengakibatkan kematian terhadap serangga. (sampan, 2014).

Nilai LD50 Mat Elektrik Kulit Buah Duku (Lansium domesticum corr) terhadap Kematian Nyamuk Culex sp LD50 (lethal dose 50) adalah dosis yang mematikan/lethal yang mematikan $50 \%$ hewan coba jika diberikan melalui mulut (oral) atau diserap melalui kulit (dermal) atau terhisap melalui pernafasan (inhalasi). (Ditjen, p2\&PL., 2012).

Hasil pengolahan data pada uji probit untuk nilai $L_{50}$ uji toksisitas kulit buah duku (Lansium domesticum corr) terhadap nyamuk Culex sp didapatkan hasil bahwa berat yang mampu membunuh $50 \%$ dari nyamuk Culex $s p$ selama 60 menit perlakuan memiliki estimasi nilai Lethal dose ( $\left.L_{50}\right)$ pada berat 0,392 yang menyebabkan kematian $50 \%$ nyamuk Culex sp. Semakin kecil nilai $\mathrm{LD}_{50}$ maka semakin beracun suatu insektisida tersebut (Ditjen, P2\&PL., 2012).

\section{KESIMPULAN}

Mat kulit buah duku (Lansium domesticum corr) dapat digunakan sebagai pengusir nyamuk Culex $s p$. Nilai $\mathrm{LD}_{50}$ pada hasil berat mat elektrik kulit buah duku (Lansium domesticum corr) yang dapat 
membunuh $50 \%$ populasi nyamuk Culex $s p$ selama 60 menit sebesar 0,392 gram.

\section{SARAN}

Bagi masyarakat dapat memanfaatkan kulit buah duku (lansium domesticum corr) sebagai indesktisida nabati dengan metode mat elektrik untuk pengendalian nyamuk Culex sp.

\section{DAFTAR PUSTAKA}

Dinas Kesehatan Provinsi Jawa Timur. 2016. Profil Kesehatan Provinsi Jawa Timur Tahun 2016. Surabaya: Dinas Kesehatan Provinsi Jawa Timur, Daftar lampiran tabel 23

Ditjen, p2\&PL., 2012. Pedoman Penggunaan Insektisida (Pestisida) DalamPengendalian Vektor. Jakarta: Kemenkes RI

Jaya, I. (2017). Imperta cylindrica ) SEBAGAI ANTI NYAMUK ELEKTRIK TERHADAPNYAMUK Aedes aegypti egypti.

Kemenkes RI. 2016. Info DATIN.Situasi Filariasis di Indonesia tahun 2015.ISSN 2442-7659.

Masriadi, H. 2017., Epidemiologi Penyakit Menular. Depok: Rajawali

Notoatmojo, Soekidjo, 2012. Metodologi Penelitian Kesehatan. Jakarta, Rineka Cipta
Pemkot surababaya.2016. Profil Kesehata tahun 2016 .Surabaya

Peraturan Mentri Kesehatan Republik Indonesia. 2014. Penanggulangan Filariasis. Jakarta: Permenkes RI

Sampan, Fina E. S. dkk. 2014. Uji Efektifitas Ekstrak Kulit Buah Duku (Lansium Domesticum Corr) Sebagai Anti Nyamuk Elektrik terhadap Daya Bunuh Nyamuk Aedes aegeptri. Fakultas Ilmu-ilmu Kesehatan dan Keolahragaan. Universitas Negri Gorontalo

Sucipto, Dani C., 2011. Vektor Penyakit Tropis. Yogtakarta: Gosyen Publishing

WHOPES, 2009. Guidelines For Efficacy Tasting Of Household Insecticide Products: Mosquito Coils, Vaporizer Mats, Liquid Vaporizers, Ambient Emators and Aerosols.

http://www. who.int/whopes/resources/w ho htm ntd whopes 2009.3/en/. Diakses 10 November 2018

WHO, 2018. Lymphatic Filariasis. https://www.who.int/newsroom/fact-sheets/detail/lymphaticfilariasis. Diakses 26 Januari 2019

Yudhastuti, Ririh., 2011. Pengendalian Vektor dan Rodent. Surabaya: Pustaka Melati 